\title{
Impact of COVID-19 and Associated Preventive Measures on Cardiometabolic Risk Factors in South Korea
}

\author{
Minji Sohn', Bo Kyung Koo², Ho II Yoon', Kyoung-Ho Song' ${ }^{1}$ Eu Suk Kim', Hong Bin Kim¹, Soo Lim,** \\ ${ }^{1}$ Department of Internal Medicine, Seoul National University Bundang Hospital, Seoul National University College of Medicine, Seongnam; ${ }^{2}$ Department of Internal \\ Medicine, SMG-SNU Boramae Medical Center, Seoul National University College of Medicine, Seoul, Korea
}

Background: During the coronavirus disease 2019 (COVID-19) pandemic, preventive measures mandated by government policies have included the closure of exercise facilities and movement restriction, which can lead to an unhealthy lifestyle. We investigated the effect of these preventive measures on metabolic parameters in individuals with cardiometabolic disorders.

Methods: In this retrospective, observational study of patients who visited the hospital at least twice a year for the past 4 years, changes in cardiometabolic factors during the COVID-19 pandemic (2019-2020) were compared with changes in the same cohort at the same annual time points during the previous seasons of 2016-2019.

Results: A total of 1,485 individuals with a mean age of $61.8 \pm 11.7$ years were included in the analyses. During the COVID-19 pandemic, the number of patients whose metabolic syndrome worsened increased significantly by $21 \%$ compared with the $2018-2019$ season. Body mass index increased by $0.09 \pm 1.16 \mathrm{~kg} / \mathrm{m}^{2}$ in the 2019 2020 pandemic period, whereas it decreased by $-0.39 \pm 3.03 \mathrm{~kg} / \mathrm{m}^{2}$ in $2018-2019$ and by $-0.34 \pm 2.18 \mathrm{~kg} / \mathrm{m}^{2}$ in 2017-2018 (both $P<0.05$ ). Systolic blood pressure increased by $2.6 \pm 18.2 \mathrm{mmHg}$ in the COVID-19 pandemic period, while it decreased in the three antecedent seasons (all $P<0.05$ ). Lipid profiles worsened in the pandemic period compared with the previous years. Framingham coronary heart disease risk score also increased significantly.

Conclusion: Nationwide strategies to maintain cardiometabolic health are necessary during contagious disease pandemics like COVID-19 to mitigate the adverse health effects of pandemic-preventative strategies.

Key words: COVID-19, Metabolic syndrome, Obesity, Dyslipidemia, Coronary heart disease
Received April 12, 2021

Reviewed May 15, 2021

Accepted May 17, 2021

*Corresponding author

Soo Lim

(1)

https://orcid.org/0000-0002-4137-1671

Department of Internal Medicine, Seoul National University Bundang Hospital, Seoul National University College of Medicine, 82 Gumi-ro 173beon-gil, Bundang-gu, Seongnam 13620, Korea Tel: +82-31-787-7035

Fax: +82-31-787-4051

E-mail: limsoo@snu.ac.kr

\section{INTRODUCTION}

Severe acute respiratory syndrome coronavirus 2 (SARS-CoV-2) infection causes coronavirus disease 2019 (COVID-19). As of February 23, 2021, 111,365,509 cases and 2,466,239 deaths have been confirmed. ${ }^{1}$ SARS-CoV-2 induces mild symptoms in the initial stage but has the potential to result in severe illness, including systemic inflammatory response syndrome, acute respiratory distress syndrome, multiorgan involvement, and shock. ${ }^{2}$
In South Korea, the COVID-19 pandemic broke out in February 2020 (Fig. 1A), and in response the government raised the crisis alert level to "severe," the highest (Fig. 1B). Infectious disease prevention and control measures included shutting down public facilities such as libraries and sports centers, and suspending school attendance. The public was requested to refrain from going outside unnecessarily, except for commuting to/from work, and to maintain at least 1-2-m distance from others in the workplace. ${ }^{3}$ As a result, personal movements decreased by $38.1 \%$ during the early pe-

Copyright (C) 2021 Korean Society for the Study of Obesity

(a) This is an Open Access article distributed under the terms of the Creative Commons Attribution Non-Commercial License (https://creativecommons.org/licenses/by-nc/4.o/) which permits unrestricted non-commercial use, distribution, and reproduction in any medium, provided the original work is properly cited. 


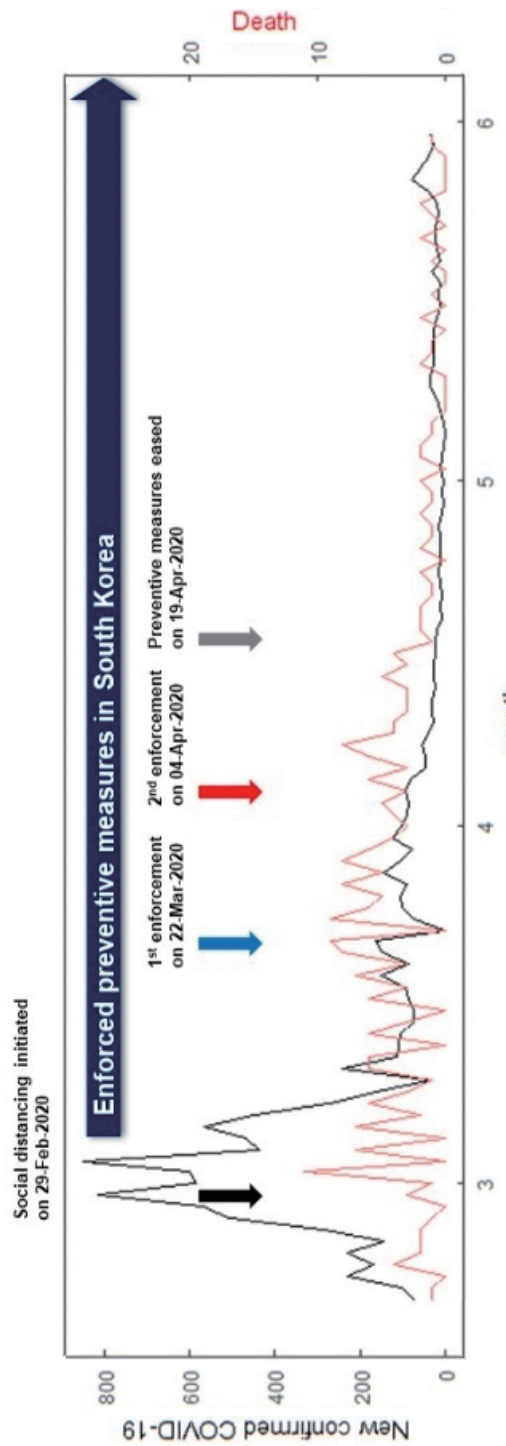

4

J Obes Metab Syndr 2021;30:248-260

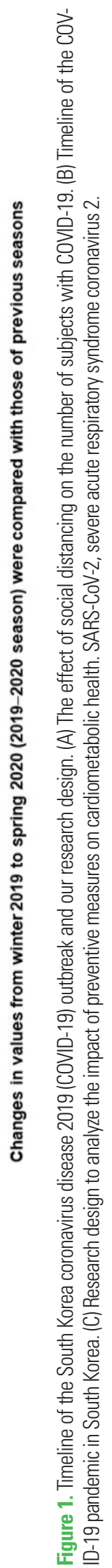

(0)

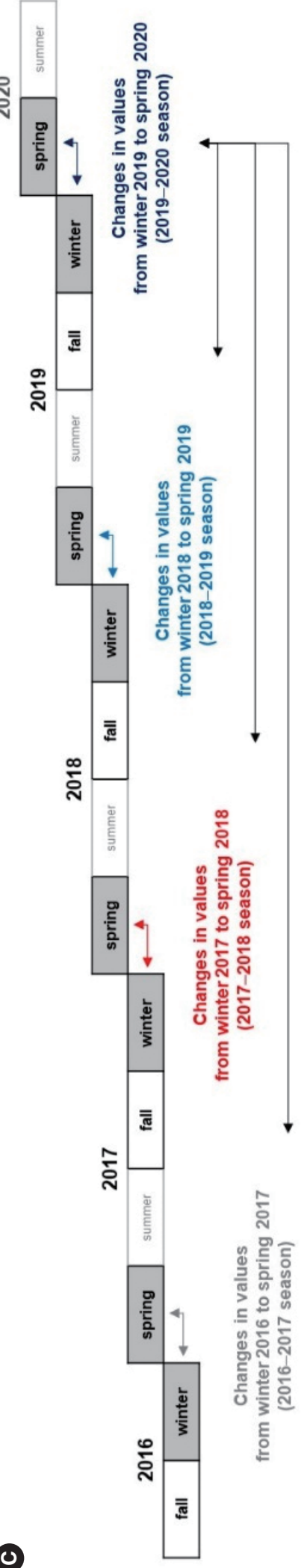

https://www.jomes.org 
riod of the COVID-19 outbreak compared with before the outbreak based on mobile big data. ${ }^{4}$ Thanks to these preventive measures and cooperation from the general public, the number of daily new domestic infections in South Korea fell dramatically.

In the early days following the introduction of these measures, people were cautious and made lifestyle changes, but became less cautious over time. The infection rate dropped from 441 to 47 per day as of October 15, 2020 —although it has risen to 621 per day as of February 17, 2021. ${ }^{5}$ The Korean government has again raised the crisis alert level, which means stricter observation of social distancing, and a ban on staying in public places and in indoor health facilities, cafes, bars, and any places where people gather together. Large-scale gatherings are also prohibited (see http://ncov.mohw. go.kr/en/).

Several groups, including ours, have reported that old age, diabetes mellitus (DM), cardiovascular disease, hypertension, metabolic syndrome, and obesity are risk factors for fatal outcomes of COVID-19. ${ }^{6}$ People with coronary heart disease (CHD) or DM have a higher chance of being admitted to intensive care units, needing mechanical ventilation, or of dying due to SARS-CoV-2 infection. ${ }^{7}$ Because elevated glucose levels directly promote SARS-CoV-2 replication, which essentially requires glycolysis in the host, ${ }^{8}$ patients with uncontrolled DM are expected to experience more rapid progression of COVID-19. ${ }^{6}$ Moreover, metabolic syndrome induces host immune dysregulation and a proinflammatory milieu, leading to increased severity and mortality when infected with SARS$\mathrm{CoV}-2$ via vasculopathy, thrombosis, and coagulopathy. ${ }^{9}$

Conversely, inactivity associated with social and physical distancing to prevent the spread of COVID-19 might impair metabolic control..$^{10}$ Thus, preventive measures initiated as a response to the COVID-19 pandemic, such as preventing people from going outdoors and shutting down exercise facilities, are likely to have a negative influence on public lifestyle and behaviors, ${ }^{11}$ which could adversely affect cardiometabolic health. ${ }^{12}$ So far, the impacts of COVID-19 prevention and related control measures on chronic diseases have not been evaluated. Here, we hypothesized that the COVID-19 pandemic and associated unhealthy lifestyles would negatively influence metabolic parameters in individuals with cardiometabolic risk factors.

\section{METHODS}

\section{Study design and population}

This was a single-center, retrospective, observational cohort study conducted at Seoul National University Bundang Hospital (SNUBH) in South Korea. The study was approved by our independent Ethics Committee/Institutional Review Board (SNUBH: B-2008/630-102). The study population was adults aged over 19 years with diagnosed cardiometabolic risk factors including impaired glucose metabolism, hypertension, dyslipidemia, or obesity who visited the outpatient clinic of the Department of Endocrinology and Metabolism at SNUBH. Patients who visited from September 1, 2016, to May 31, 2020, at least twice a year, before and after February, the time of South Korea's COVID-19 outbreak, were further selected. In all, 7,094 patients with International Classification of Diseases Tenth Edition (ICD-10) diagnostic codes of E10-14 for DM, I10 and I15 for hypertension, E78 for dyslipidemia, and/or E66 for obesity were identified using the hospital database and a clinical data warehouse $(\mathrm{CDW}){ }^{13}$

Patients who were hospitalized for a major illness or major surgery, and who received dialysis during the study period were excluded (Supplementary Fig. 1). Major surgery was defined as surgery performed for neoplasms, diseases of blood-forming organs, circulatory, or digestive systems, or injuries determined by ICD-10 codes starting with C, D, I, K, or S. The number of patients hospitalized in the endocrinology unit did not differ between years, but these patients were excluded from the study analysis because hospitalization for intensive glucose-lowering therapy might have hindered identifying the impact of pandemic preventive measures. The number of patients who visited the outpatient clinic during the COVID-19 pandemic was similar to the number who visited the clinic during the same time frame in previous years. Thus, loss to follow-up during the study period is not a limitation of the current study.

\section{Collection of clinical parameters}

The Korean government reinforced the national public health emergency response by emphasizing the need to maintain social distancing on February 29, 2020. Therefore, we divided clinical data according to date of examination as follows: (1) from Septem- 
ber 2019 to November 2019 ("fall"); (2) from December 2019 to February 2020 ("winter"), and (3) from March 2020 to May ("spring"), and compared clinical parameters in each season with those of the previous years (2016-2017, 2017-2018, and 20182019) (Fig. 1C).

Patients' outpatient care information, admission information, clinical laboratory values, anthropometric measurements, and prescription information were retrieved from the CDW. Body weight, body mass index (BMI), systolic and diastolic blood pressure (SBP and DBP, respectively), and metabolic profiles such as levels of fasting plasma glucose (FPG), glycated hemoglobin (HbAlc), total cholesterol, triglycerides (TG), high-density lipoprotein cholesterol (HDL-C), and low-density lipoprotein cholesterol (LDL-C) in each season were summarized as means for each individual prior to analysis. Data cleaning was performed for manually inputted anthropometrics into the system at the time of care. Values that were obviously inaccurate, provided in ranges, or physically impossible and considered to be typographic errors were discarded, such as height $>300 \mathrm{~cm}$, body weight $<10 \mathrm{~kg}$, and DBP $>$ SBP. For clinical values with a high standard deviation (SD) in individuals, such as SBP SD $>50$ or weight $\mathrm{SD}>10$, consecutive measurements were checked further to determine whether this was an error or a change in clinical status. Height was converted to a 4-year mean measure for each patient considering measurement variation. Then, BMI was recalculated as mass (in kilograms) divided by height (in meters) squared. The use of medications for DM, hypertension, and dyslipidemia was also investigated.

\section{Anthropometric and biochemical parameters}

Anthropometric and biochemical parameters were measured in SNUBH as reported previously. ${ }^{14}$ Height and body weight were measured using standard methods with the subjects in light clothing. FPG concentration was measured using the glucose oxidase method (747 Clinical Chemistry Analyzer; Hitachi, Tokyo, Japan). $\mathrm{HbA1c}$ levels were measured using a Bio-Rad Variant II Turbo High-Performance Liquid Chromatography Analyzer (Bio-Rad, Hercules, CA, USA) in a National Glycohemoglobin Standardization Program level II certified laboratory. Total cholesterol, TG, HDL-C, and LDL-C levels were measured using a 747 Clinical Chemistry Analyzer (Hitachi).
Metabolic syndrome was defined using modified Adult Treatment Panel III criteria. ${ }^{15}$ Because waist circumference data were limited, the World Health Organization Asia-Pacific criteria for BMI were used; ${ }^{16}$ metabolic syndrome was diagnosed as the existence of at least three of the following abnormal findings: (1) FPG $\geq 100$ $\mathrm{mg} / \mathrm{dL}$ and/or taking antidiabetic agents; (2) SBP $\geq 130 \mathrm{mmHg}$, DBP $\geq 85 \mathrm{mmHg}$, and/or taking antihypertensive agents; (3) TG $\geq 150 \mathrm{mg} / \mathrm{dL}$ and/or taking lipid-lowering agents; (4) HDL-C $\leq 40 \mathrm{mg} / \mathrm{dL}$ in men and HDL-C $\leq 50 \mathrm{mg} / \mathrm{dL}$ in women, and (5) $\mathrm{BMI} \geq 23 \mathrm{~kg} / \mathrm{m}^{2}$ and/or taking anti-obesity agents. Patients with $\mathrm{HbAlc} \geq 6.5 \%$ and/or taking antidiabetic agents were classified according to the status of DM treatment.

Ten-year CHD risk was calculated using the Framingham risk score (FRS). ${ }^{17}$ The correlation of calculated CHD risk with actual 10-year $\mathrm{CHD}$ was shown to be stronger when using total cholesterol levels than when using LDL-C scoring in Korean subjects. ${ }^{18}$ Therefore, FRS in this study was calculated using TC level.

\section{Statistics}

All data were obtained for the same subjects in all four periods/ seasons. Continuous variables are summarized as mean $\pm \mathrm{SD}$ and categorical variables are shown as numbers and percentages of subjects. Normality of data distributions were evaluated using the Shapiro-Wilk test and by histograms; all variables were found to be normally distributed with bell-shaped symmetric graphs. Student ttest was used to assess the significance of differences in continuous variables between groups while the chi-square test was used to assess the significance of differences in categorical variables between groups. Changes in values from winter 2019 to spring 2020 for the 2019-2020 season and those from the same time frame from 2016 to 2019 for the 2016-2017, 2017-2018, and 2018-2019 seasons were obtained. Values in the 2019-2020 season were compared with those of each previous season using paired Student t-tests with Holm-Bonferroni correction. Because the patient follow-up period was up to 6 months, not all the patients had complete seasonal data. To reduce bias, missing values were imputed using multiple imputation by chained equations for those patients who did not have complete test results. ${ }^{19}$ Imputed data were used to analyze changes in values. Relative risk (RR) was calculated as the number of patients who showed worse metabolic syndrome components in 
Table 1. Patients' characteristics

\begin{tabular}{|c|c|c|c|c|}
\hline Variable & Winter 2016 & Winter 2017 & Winter 2018 & Winter 2019 \\
\hline Weight (kg) & $67.1 \pm 12.7$ & $67.9 \pm 12.4$ & $67.5 \pm 12.3$ & $66.2 \pm 12.0^{t, \pm}$ \\
\hline BMI $\left(\mathrm{kg} / \mathrm{m}^{2}\right)$ & $25.2 \pm 3.3$ & $25.5 \pm 3.3$ & $25.4 \pm 3.4$ & $24.9 \pm 3.2^{*,+, \pm}$ \\
\hline $\mathrm{SBP}(\mathrm{mmHg})$ & $133.0 \pm 14.9$ & $135.2 \pm 14.8^{*}$ & $136.7 \pm 15.0^{*,+}$ & $136.8 \pm 16.0^{*, t}$ \\
\hline $\mathrm{DBP}(\mathrm{mmHg})$ & $77.6 \pm 10.5$ & $78.5 \pm 10.1$ & $77.6 \pm 11.2$ & $77 \pm 11.7^{\dagger}$ \\
\hline FPG (mg/dL) & $141.3 \pm 41.5$ & $147 \pm 43.8^{*}$ & $145.6 \pm 44.5^{*}$ & $143.1 \pm 39.9^{\dagger}$ \\
\hline $\mathrm{HbA1c}(\%)$ & $7.22 \pm 1.3$ & $7.28 \pm 1.19$ & $7.34 \pm 1.23^{*}$ & $7.27 \pm 1.24$ \\
\hline $\mathrm{TC}(\mathrm{mg} / \mathrm{dL})$ & $165.9 \pm 37.0$ & $165.7 \pm 38.8$ & $162.6 \pm 37.1^{*}$ & $162.9 \pm 39.7$ \\
\hline $\mathrm{TG}$ (mg/dL) & $148.1 \pm 83.5$ & $147.6 \pm 96.1$ & $139 \pm 79.3^{*}$ & $137.8 \pm 91.9$ \\
\hline HDL-C (mg/dL) & $50.5 \pm 10.9$ & $51.1 \pm 11.4$ & $49.6 \pm 11.7^{*}$ & $52.2 \pm 12.8^{*,+, \pm}$ \\
\hline LDL-C (mg/dL) & $91.5 \pm 26.8$ & $90.9 \pm 28.3$ & $96.8 \pm 26.8^{*, t}$ & $97.4 \pm 28.3^{*,+}$ \\
\hline \multicolumn{5}{|l|}{ Comorbid status } \\
\hline Diabetes mellitus & 1,348 (90.8) & 1,348 (90.8) & 1,348 (90.8) & $1,350(90.9)$ \\
\hline Hypertension & 814 (54.8) & 834 (56.2) & $840(56.6)$ & 849 (57.2) \\
\hline Dyslipidemia & 1,162 (78.2) & 1,158 (78.0) & 1,163 (78.3) & $1,169(78.7)$ \\
\hline Obesity & 740 (49.8) & $778(52.4)$ & $753(50.7)$ & 689 (46.4) \\
\hline \multicolumn{5}{|l|}{ Concomitant medication } \\
\hline Antidiabetic agent & $1,159(78.0)$ & 1,181 (79.5) & $1,207(81.3)^{*}$ & $1,212(81.6)^{*}$ \\
\hline Insulin & 190 (12.8) & 192 (12.9) & $188(12.7)$ & $218(14.7)$ \\
\hline Metformin & $1,087(73.2)$ & $1,100(74.1)$ & $1,123(75.6)$ & $1,113(74.9)$ \\
\hline DPP4 inhibitor & 590 (39.7) & 570 (38.4) & 561 (37.8) & 557 (37.5) \\
\hline SGLT-2 inhibitor & $79(5.3)$ & $102(6.9)$ & $174(11.7)^{*,+}$ & $209(14.1)^{*, t}$ \\
\hline Sulfonylurea & $485(32.7)$ & $511(34.4)$ & $519(34.9)$ & $520(35.0)$ \\
\hline Thiazolidinedione & $92(6.2)$ & $84(5.7)$ & $73(4.9)$ & $68(4.6)$ \\
\hline$\alpha$-Glucosidase inhibitor & $6(0.4)$ & $5(0.3)$ & $5(0.3)$ & $4(0.3)$ \\
\hline GLP-1 RA & $4(0.3)$ & $6(0.4)$ & $14(0.9)$ & $14(0.9)^{*}$ \\
\hline Antihypertensive agent & $726(48.9)$ & $753(50.7)$ & $763(51.4)$ & $767(51.6)$ \\
\hline ACE inhibitor & $65(4.4)$ & $64(4.3)$ & $64(4.3)$ & $58(3.9)$ \\
\hline ARB & 554 (37.3) & $556(37.4)$ & $570(38.4)$ & $580(39.1)$ \\
\hline ССВ & $398(26.8)$ & $421(28.4)$ & $429(28.9)$ & $431(29.0)$ \\
\hline Diuretic & $92(6.2)$ & $101(6.8)$ & $103(6.9)$ & $109(7.3)$ \\
\hline$\beta$-blocker & $90(6.1)$ & $108(7.3)$ & $108(7.3)$ & $96(6.5)$ \\
\hline Lipid-lowering agent & $887(59.7)$ & $888(59.8)$ & $891(60.0)$ & $907(61.1)$ \\
\hline Statin & $878(59.1)$ & $877(59.1)$ & $880(59.3)$ & $893(60.1)$ \\
\hline Ezetimibe & $160(10.8)$ & $171(11.5)$ & $186(12.5)$ & $182(12.3)$ \\
\hline PCSK9 inhibitor & 0 & 0 & 0 & $1(0.1)$ \\
\hline Fibrate & $36(2.4)$ & $57(3.8)$ & $28(1.9)^{\dagger}$ & $33(2.2)^{\dagger}$ \\
\hline Cholestyramine resin & $1(0.1)$ & 0 & $1(0.1)$ & $1(0.1)$ \\
\hline Nicotinic acid & $1(0.1)$ & 0 & 0 & 0 \\
\hline Omega 3 fatty acid & $15(1.0)$ & $12(0.8)$ & $15(1.0)$ & $21(1.4)$ \\
\hline Anti-obesity agent & $1(0.1)$ & $2(0.1)$ & $7(0.5)^{*}$ & $41(2.8)^{*,+, \neq}$ \\
\hline Liraglutide 3 mg & 0 & 0 & $7(0.5)^{*,+}$ & $40(2.7)^{*,+, \neq}$ \\
\hline Orlistat & $1(0.1)$ & 0 & 0 & 0 \\
\hline Phentermine/topiramate & 0 & $1(0.1)$ & 0 & 0 \\
\hline Naltrexone/bupropion & 0 & $1(0.1)$ & 0 & $1(0.1)$ \\
\hline
\end{tabular}

Values are presented as mean \pm standard deviation or number (\%).

${ }^{*} P<0.05$, compared with the fall and winter of $2016 ;{ }^{\dagger} P<0.05$, compared with the fall and winter of 2017 ; ${ }^{\ddagger} P<0.05$, compared with the fall and winter of 2018 .

$\mathrm{BMI}$, body mass index; SBP, systolic blood pressure; DBP, diastolic blood pressure; FPG, fasting plasma glucose; HbA1C, glycated hemoglobin; TC, total cholesterol; TG, triglycerides; HDL-C, high-density lipoprotein cholesterol; LDL-C, low-density lipoprotein cholesterol; DPP4, dipeptidyl peptidase-4; SGLT-2, sodium-glucose co-transporter 2; GLP-1 RA, glucagonlike peptide-1 receptor agonist; ACE, angiotensin-converting enzyme; ARB, angiotensin II receptor blocker; CCB, calcium channel blocker; PCSK9, proprotein convertase subtilisin/ kexin type 9. 
the 2019-2020 season than in the 2018-2019 season, and expressed as $\mathrm{RR}$ with a $95 \%$ confidence interval (CI). Subgroup comparisons of risk estimates by age and sex were made with tests of interactions. ${ }^{20}$ Statistical significance was defined as a two-sided $P$-value $<0.05$. All analyses were performed using R software version 4.0.2 (R Development Core Team, Vienna, Austria) and RStudio version 1.3. 1056 (RStudio Inc., Boston, MA, USA).

A

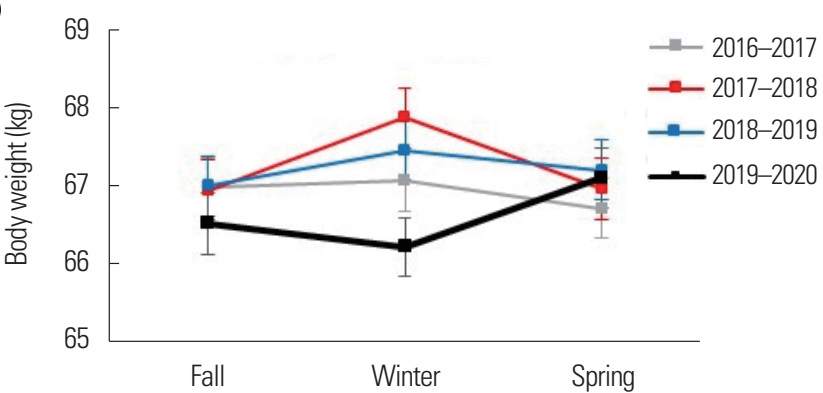

C

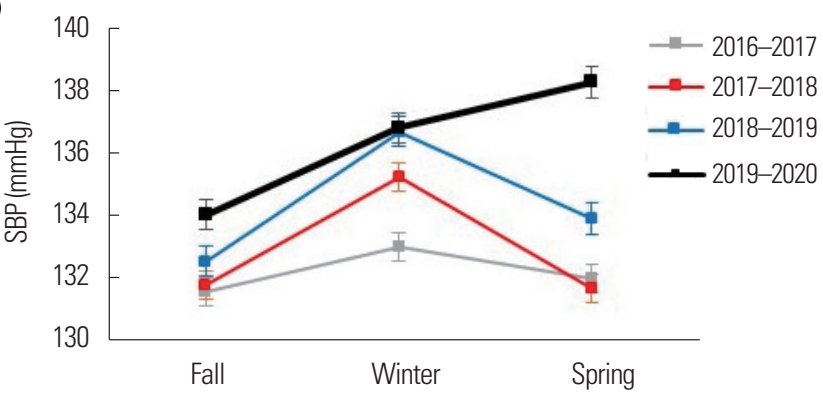

E

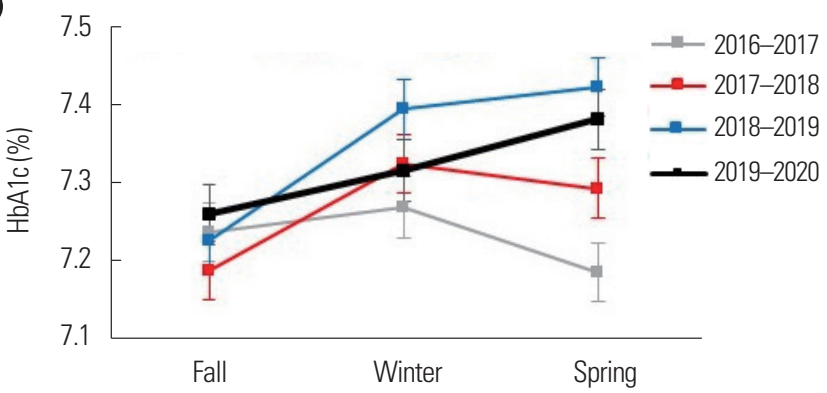

G

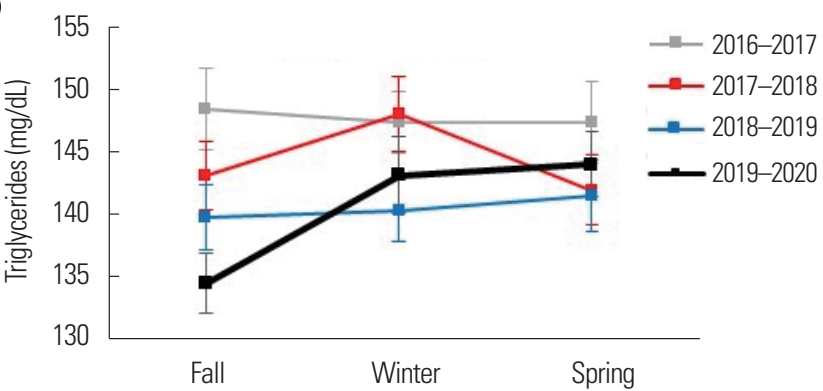

\section{RESULTS}

\section{Patient characteristics}

A total of 1,485 patients with a mean age of $61.8 \pm 11.7$ years in September 2016 were included in this study. The proportions of men and women were almost equal (male: $\mathrm{n}=757,51.0 \%$ ). All patients had at least one chronic cardiometabolic impairment such as

B

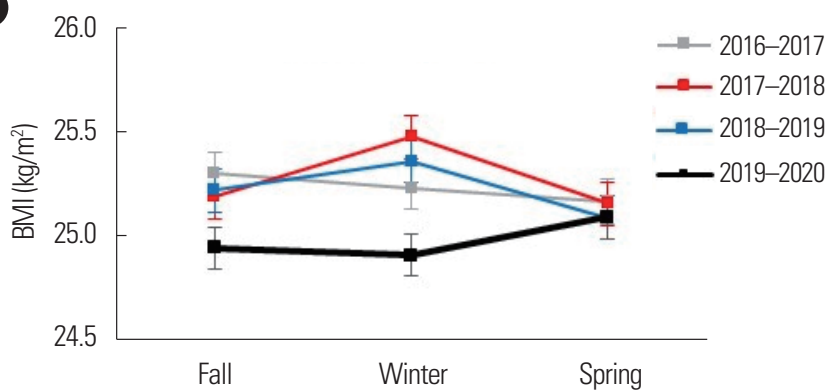

D

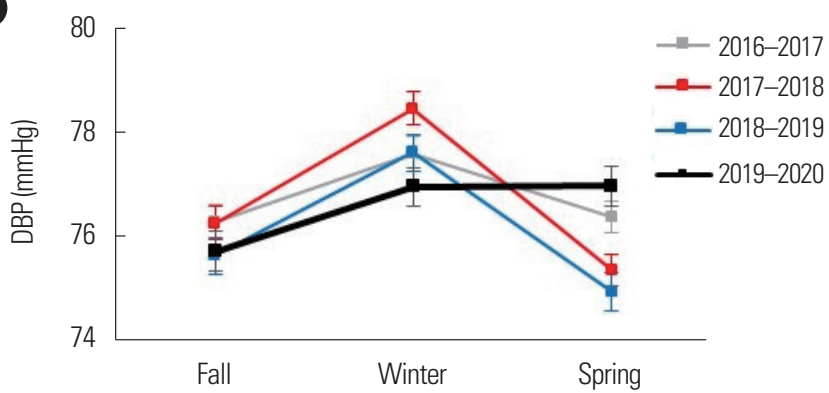

$\mathbf{F}$

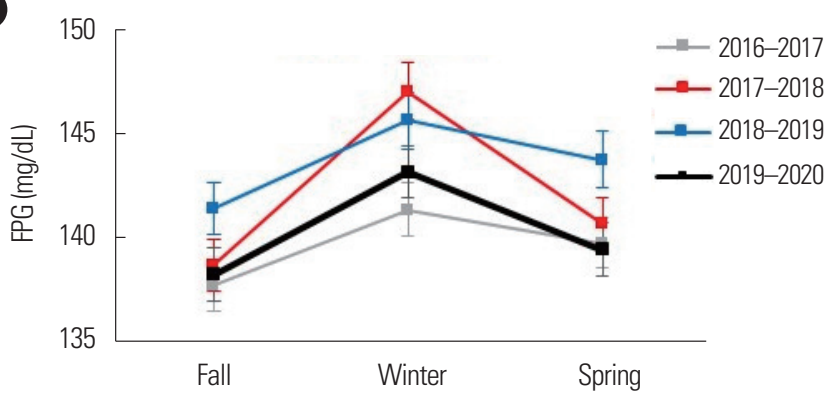

$\boldsymbol{H}$

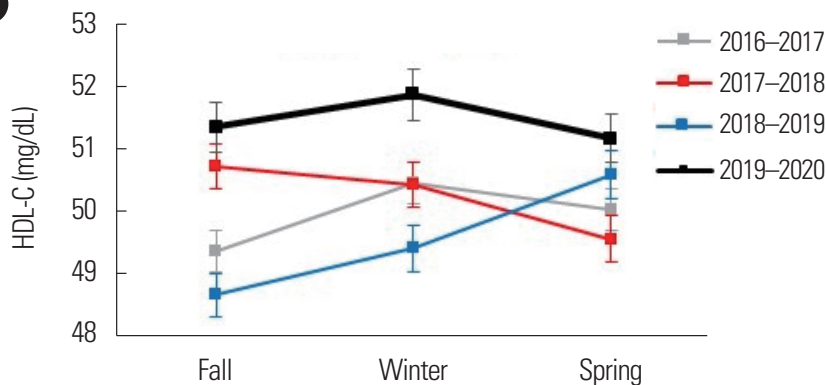

Figure 2. Changes in metabolic syndrome components before (i.e., fall and winter, 2019) and during (i.e., spring, 2020) the coronavirus disease 2019 (COVID-19) pandemic in South Korea: (A) body weight, (B) body mass index (BMI), (C) systolic blood pressure (SBP), (D) diastolic blood pressure (DBP), (E) glycated hemoglobin (HbA1c), (F) fasting plasma glucose (FPG), (G) triglycerides, (H) high-density lipoprotein cholesterol (HDL-C). 
DM, hypertension, dyslipidemia, or obesity at baseline (Table 1). The number of comorbid diseases tended to increase with time. Total use of antidiabetic agents increased in 2019 compared with 2016. Total use of anti-obesity agents increased in 2019-2020 compared with the previous 3 years. Usage of recently approved antidiabetic drugs in Korea, namely sodium-glucose co-transporter 2 (SGLT-2) inhibitors and glucagon-like peptide-1 receptor agonists (GLP-1 RAs), increased in 2019-2020 (Table 1).

\section{Changes in cardiometabolic risk factors during the COVID-19 pandemic}

Raw values of cardiometabolic risk components before and during the COVID-19 pandemic and preventive measures are shown in Fig. 2. The degree of increase in body weight, BMI, SBP, and DBP values was highest in the spring of 2020 compared with the springs of other years. The increase in $\mathrm{HbAlc}$ levels was most prominent in the most recent seasons, ranging from $7.27 \% \pm 1.24 \%$ in the winter of 2019 to $7.33 \% \pm 1.25 \%$ in the spring of 2020 (20192020 season) compared with the other seasons. Differences in levels of other factors-FPG, TG, and HDL-C—-were similar across all four years. Differences in cardiometabolic risk factors are shown in Table 2. SBP and total cholesterol measures increased significantly

Table 2. Changes in metabolic syndrome components before (winter) and during (spring) the South Korea COVID-19 pandemic

\begin{tabular}{|c|c|c|c|c|}
\hline Variable & $\begin{array}{c}\text { 2016-2017 } \\
\text { Change }\end{array}$ & $\begin{array}{l}\text { 2017-2018 } \\
\text { Change }\end{array}$ & $\begin{array}{l}\text { 2018-2019 } \\
\text { Change }\end{array}$ & $\begin{array}{l}\text { 2019-2020 } \\
\text { Change }\end{array}$ \\
\hline Weight (kg) & $-0.07 \pm 5.12$ & $-0.89 \pm 5.94^{*}$ & $-1.04 \pm 7.75^{*}$ & $0.21 \pm 3.05^{t, \pm}$ \\
\hline BMI (kg/m²) & $-0.02 \pm 1.98$ & $-0.34 \pm 2.18^{*}$ & $-0.39 \pm 3.03^{*}$ & $0.09 \pm 1.16^{t . \pm}$ \\
\hline $\mathrm{SBP}(\mathrm{mmHg})$ & $-0.7 \pm 14.3$ & $-2.8 \pm 14.3^{*}$ & $-1.4 \pm 16.5$ & $2.6 \pm 18.2^{*,+, \pm}$ \\
\hline $\mathrm{DBP}(\mathrm{mmHg})$ & $-1.2 \pm 10.5$ & $-2.6 \pm 9.6^{*}$ & $-1.7 \pm 11.8$ & $-0.4 \pm 11.9^{t . \neq}$ \\
\hline $\mathrm{FPG}(\mathrm{mg} / \mathrm{dL})$ & $-0.7 \pm 36.8$ & $-3.5 \pm 37.4$ & $-0.3 \pm 41.6$ & $-2.3 \pm 36.2$ \\
\hline HbA1c (\%) & $-0.04 \pm 0.82$ & $0.03 \pm 0.79$ & $0.05 \pm 0.78^{*}$ & $0.07 \pm 0.93^{*}$ \\
\hline $\mathrm{TC}$ (mg/dL) & $-1.1 \pm 25.9$ & $-0.2 \pm 30.4$ & $-1.2 \pm 29.4$ & $4.1 \pm 33.2^{*, t, \pm}$ \\
\hline $\mathrm{TG}$ (mg/dL) & $-7.1 \pm 80.8$ & $-7.1 \pm 76.3$ & $1.5 \pm 72.6^{*, \dagger}$ & $4.8 \pm 69.4^{*, \dagger}$ \\
\hline $\mathrm{HDL}-\mathrm{C}(\mathrm{mg} / \mathrm{dL})$ & $-0.3 \pm 6.9$ & $-1.4 \pm 6.7^{*}$ & $1.2 \pm 7.4^{*, \dagger}$ & $-0.6 \pm 7.9^{t, \pm}$ \\
\hline LDL-C (mg/dL) & $-1.1 \pm 18.7$ & $7.4 \pm 21.6^{*}$ & $-0.1 \pm 20.9^{\dagger}$ & $3.4 \pm 24.1^{*, t, \pm}$ \\
\hline
\end{tabular}

Values are presented as mean \pm standard deviation.

${ }^{*}$ Adjusted $P<0.05$, compared with changes in 2016-2017; ${ }^{\dagger}$ Adjusted $P<0.05$, compared with changes in 2017-2018; ${ }^{\star}$ Adjusted $P<0.05$, compared with changes in 2018-2019.

COVID-19, coronavirus disease 2019; BMI, body mass index; SBP, systolic blood pressure; DBP, diastolic blood pressure; FPG, fasting plasma glucose; HbA1c, glycated hemoglobin; TC, total cholesterol; TG, triglycerides; HDL-C, high-density lipoprotein cholesterol; LDL-C, low-density lipoprotein cholesterol. during the COVID-19 pandemic when compared with the prior 3 years. Increases in body weight and BMI were statistically significant in the 2019-2020 season when compared with those in the 2017-2018 and 2018-2019 seasons.

\section{Risk of developing metabolic syndrome during the} COVID-19 pandemic

During the COVID-19 pandemic, the number of patients who developed metabolic syndrome increased: 375 (25.3\%) in 20192020 vs. 309 (20.8\%) in 2018-2019 (RR, 1.21; 95\% CI, 1.06-1.39) (Fig. 3A). Blood pressure and HbAlc levels increased significantly in the 2019-2020 COVID-19 season compared with the previous 2018-2019 season. During the COVID-19 pandemic period, subjects under 65 years developed metabolic syndrome more frequently than in previous years (RR, 1.24; 95\% CI, 1.02-1.52), though this was not true for those 65 years and older $(P=0.716)$. Among metabolic syndrome components, the low HDL-C component increased most prominently in this elderly group $(\mathrm{RR}, 1.25$; $95 \% \mathrm{CI}$, 1.01-1.54) (Fig. 3B). When compared by gender, male subjects had a higher RR for the development of metabolic syndrome during the COVID-19 pandemic (RR, 1.38; 95\% CI, 1.14-1.66) than female subjects with borderline significance $(P=0.059)$. Among metabolic syndrome components, the low HDL-C component increased significantly more in males than in females, while blood pressure and $\mathrm{HbAlc}$ level increased in males without group differences during the COVID-19 pandemic (Fig. 3C).

\section{Changes in CHD risk during the COVID-19 pandemic}

Changes in 10-year CHD risk by FRS are shown in Fig. 4. Tenyear CHD risk increased in the 2019-2020 season, but not in the other three seasons: it was $1.0 \% \pm 6.2 \%$ in $2019-2020$ vs. $-0.7 \% \pm$ $6.0 \%$ in $2018-2019,-0.2 \% \pm 5.3 \%$ in $2017-2018$, and $-0.2 \% \pm 5.4 \%$ in 2016-2017, $P<0.05$. During the COVID-19 pandemic, the number of patients with a low to intermediate 10-year $\mathrm{CHD}$ risk increased significantly compared to the risks in the three preceding seasons (176 in 2019-2020 vs. 141 in 2016-2017, 86 in 2017-2018, and 113 in 2018-2019, all $P<0.05$ ). The number of patients with a low to intermediate CHD risk in the 2017-2018 period was significantly lower than the numbers in 2016-2017 and in 2018-2019. 


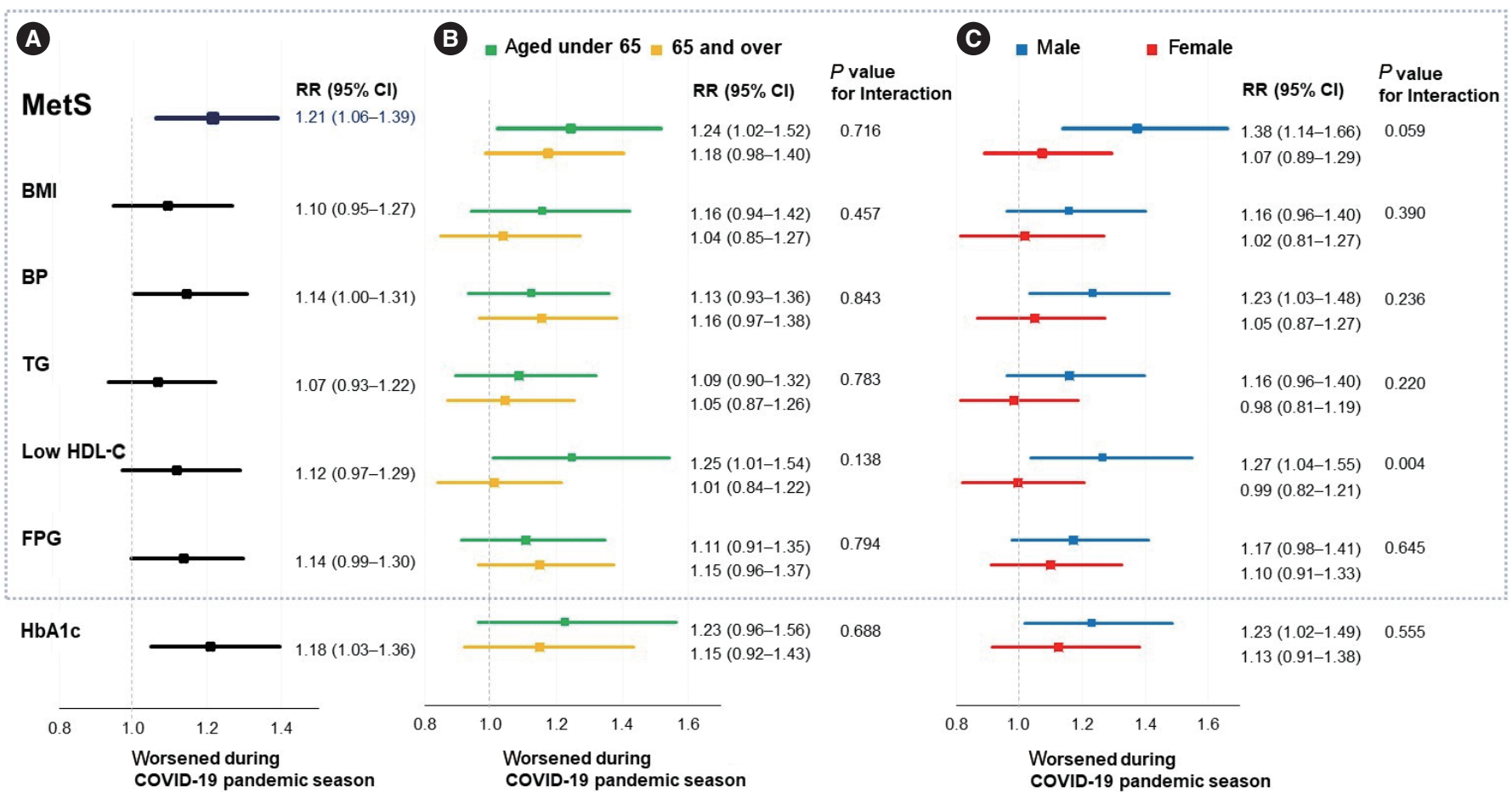

Figure 3. Relative risk (RR) of patients who had worsened metabolic syndrome components in the 2019-2020 season (coronavirus disease 2019 [COVID-19] pandemic period) when compared with that in the 2018-2019 season: (A) all patients, (B) age groups divided at 65 years, (C) sex. MetS, metabolic syndrome; BMI, body mass index; BP, blood pressure; TG, triglycerides; HDL-C, high-density lipoprotein cholesterol; FPG, fasting plasma glucose; $\mathrm{HbA1C}$, glycated hemoglobin; $\mathrm{Cl}$, confidence interval.

A

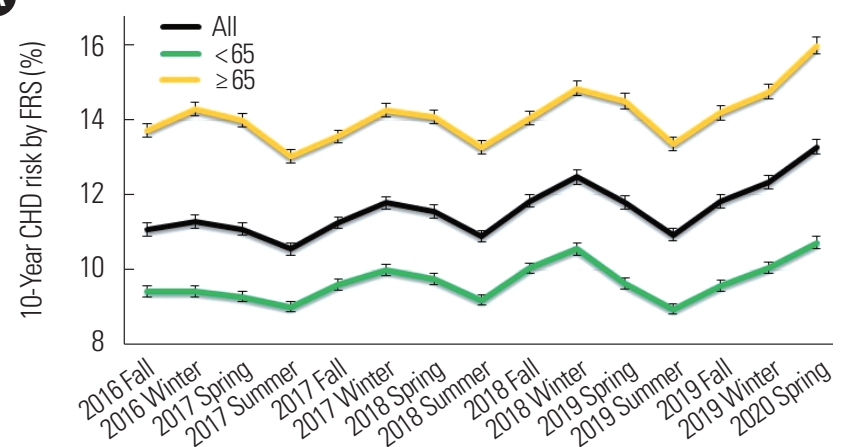

B

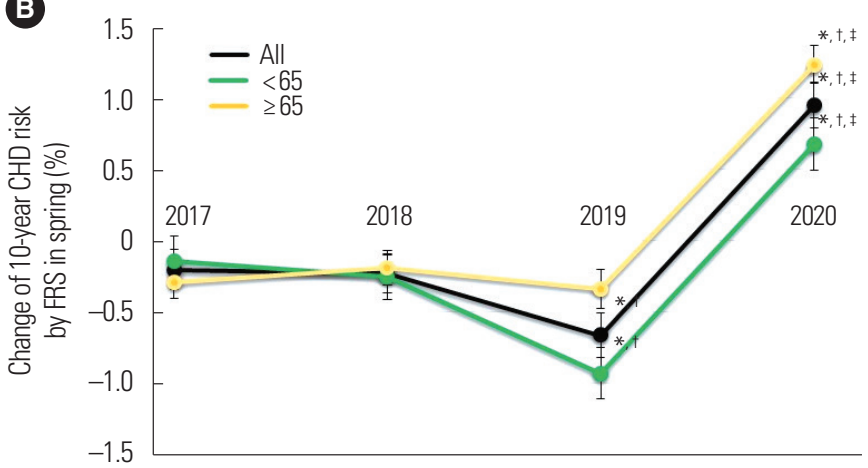

C

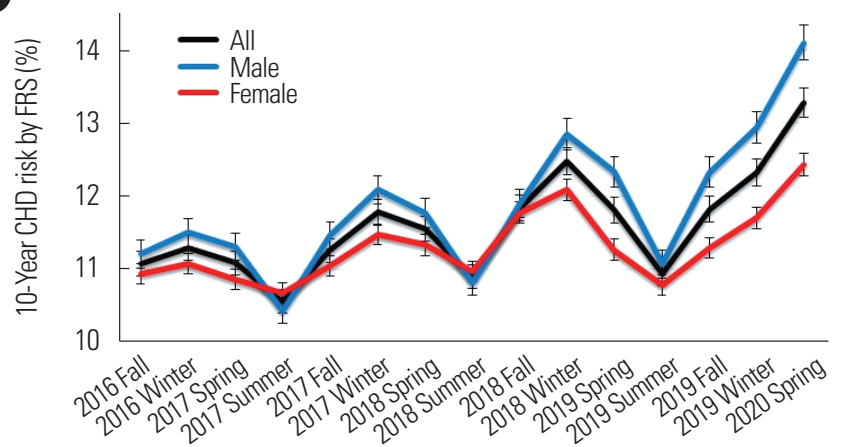

D

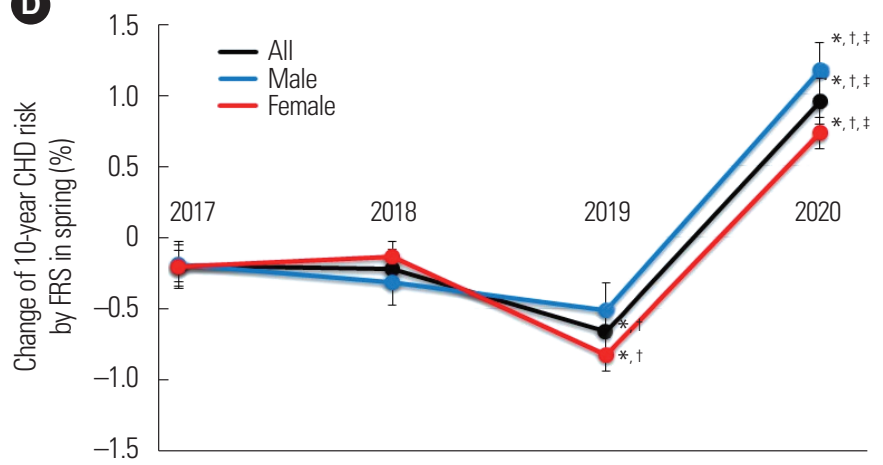

Figure 4. The 10-year coronary heart disease (CHD) risk by Framingham risk score (FRS) according to age group divided by 65 years and sex: (A, C) 10 -year CHD risk by FRS for 4 years, (B, D) changes in 10-year CHD risk by FRS before (winter 2019) and during (spring 2020) the COVID-19 pandemic in South Korea. ${ }^{*} P<0.05$ for changes with 2016-2017 (2017); ${ }^{\dagger} P<0.05$ for changes with 2017-2018 (2018); ${ }^{\ddagger} P<0.05$ for changes with 2018-2019 (2019). 


\section{DISCUSSION}

Here, we found that cardiometabolic risk factors deteriorated significantly in subjects with metabolic impairment in South Korea during the COVID-19 pandemic when preventive measures were mandated by the government. In the 2019-2020 season, the proportion of subjects with metabolic syndrome increased significantly by $21 \%$ compared with the $2018-2019$ season. Ten-year CHD risk also increased compared with the previous three years. Additionally, not only body weight and BMI, but also blood pressures, lipid profiles, and $\mathrm{HbAlc}$ changed in an unfavorable direction during the COVID-19 pandemic.

COVID-19 preventive measures implemented in South Korea included social distancing of 1-2 m, telecommuting, remote classes, and closure of exercise facilities, such as community health centers, private fitness centers, swimming pools, and parks (described in Korean at http://ncov.mohw.go.kr/en/guidelineList.do?brdId = 18 \&brdGubun = 181\&dataGubun $=$ \&ncvContSeq $=$ \&contSeq $=\&$ board_id $=\&$ gubun $=$ ). We reasoned that these measures could aggravate cardiometabolic risk factors in patients who have underlying metabolic dysregulation. According to mobile big data, ${ }^{4}$ because of the social distancing policy, personal movement of the general public in South Korea decreased by $38.1 \%$ in the 4th week of the COVID-19 outbreak (February 24-March 1, 2020) compared with the period before a confirmed COVID-19 case was identified (January 9-22, 2020). Like many countries, trips to all major destinations except personal residences in South Korea dropped significantly by 50 to $80 \%$ in early March 2020 when COVID-19 was declared a pandemic (https://kojects.com/2020/06/01/mobilitykorea-covid-19/). A recent self-report survey showed that people spent more time at home and actually gained weight during the COVID-19 pandemic. ${ }^{21}$ Acute reductions in physical activity during the COVID-19 pandemic might worsen insulin resistance and result in body weight gain. ${ }^{22}$

In addition, various public health interventions including staying at home, refraining from nonessential social activities, and school closures limit access to healthy food options. ${ }^{10}$ Based on data derived from leading food delivery apps in Korea (Baemin [https:// www.baemin.com] and Yogiyo [https://www.yogiyo.co.kr]), the number of food deliveries increased by $11 \%$ during February 1-16 compared with January 6-21 after the virus had spread across the country (https: //pulsenews.co.kr/view.php?sc $=30800$ 022\&year $=$ $2020 \&$ no $=176494)$. Popular delivered foods were fast foods such as pizza, fried chicken, French fries, and sugar-containing drinks. ${ }^{23}$ These foods are more obesogenic than homemade foods. ${ }^{24}$ More specifically, Korean-style fast foods are popular in South Korea because they are less expensive and easier to order regardless of household income level and residential location. ${ }^{25}$ Of particular concern, Korean-style fast foods contain high-carbohydrate ingredients such as white flour, white rice, and cornstarch. Increased consumption of these foods is associated with increased energy density and high glycemic load. ${ }^{26}$ Some previous studies have shown that increased consumption of fast food and sugar-containing drinks is associated with an increased risk of obesity, metabolic syndrome, and DM. ${ }^{26,27}$

From a sociological context, the COVID-19 pandemic has produced economic disruption and many households are suffering financial distress, limiting their access to healthy foods. In addition, a decrease in outdoor activities and an increase in time spent using the Internet and social network services, playing online games, and watching TV may have also had a negative impact on $\operatorname{diet}^{28}$ Thus, measures instituted to protect against the spread of COVID-19 may have contributed to a sedentary lifestyle and unhealthy nutrition among the general public.

We found that the 10-year CHD risk of patients increased during the COVID-19 pandemic in South Korea. Patients aged $\geq 65$ years displayed an increasing trend in their 10 -year $\mathrm{CHD}$ risk score $(1.2 \% \pm$ $7.1 \%, P=0.08)$ during the 2019-2020 season compared with the previous 2018-2019 season, which may have contributed to the increased mortality rate in the elderly during the COVID-19 pandemic.

In the current analysis, body weight, blood pressure, and lipid levels decreased in spring except during the 2019-2020 COVID-19 pandemic season. This is a similar finding to those reported in previous studies. ${ }^{29-31}$ Body weight was lowest during the winter of 2019, most likely due to increased usage of SGLT-2 inhibitors, GLP-1 RAs, and anti-obesity agents, specifically liraglutide. In addition, cardiometabolic risk parameters within our cohort increased significantly during the COVID-19 pandemic and institution of COVID-19 preventive measures. These findings suggest that these 
preventative measures have an unfavorable impact on cardiometabolic risk parameters. As SGLT-2 inhibitors and GLP-1 RAs reduce the incidence of cardiovascular disease, identifying the actual occurrence of cardiovascular disease with follow-up observation is necessary.

Other mechanisms have been suggested to explain the association between COVID-19 pandemic and the aggravation of metabolic profiles and increased cardiovascular risk. It is clear that the COVID-19 pandemic is having a negative influence on mental health. ${ }^{32}$ Many people are psychologically distressed due to fear of infection or dying, which might lead to systemic inflammation..$^{33}$ Limited access to exercise facilities and disruption of human relationships also increase psychological stress levels, which likely contributes to elevations in blood pressure and dysregulation of glucose homeostasis as a result of the release of stress hormones such as cortisol and catecholamines by activation of the hypothalamicpituitary-adrenal axis..$^{34}$ In fact, the sympathetic system produces increased levels of catecholamines after catastrophic events, which influence the heart and blood vessels negatively. ${ }^{35}$ In a dysregulated metabolic status, the renin-angiotensin system is inappropriately activated, which also leads to increased production of angiotensinogen (up to $30 \%$ of circulating angiotensinogen) and elevated plasma renin activity, which in turn contributes to an increase in blood pressure and impaired glucose metabolism. ${ }^{36}$ Although the effects of this pandemic may not be evident in the short term, its long-term impacts on cardiometabolic risk cannot be ignored. ${ }^{12}$

In the current study, males had a significantly increased risk of metabolic syndrome and low HDL-C during the COVID-19 pandemic compared with previous seasons. In general, middle-aged men are more involved in economic activities than women or elderly populations in Korea, ${ }^{37}$ and may therefore have been more affected by current preventive measure than females, which could explain the above findings.

Considering the deterioration in cardiometabolic profiles during the COVID-19 pandemic, physicians should focus on patients with metabolic impairment to prevent future adverse cardiovascular events. Elevated release of cytokines in metabolic syndrome status is likely to provoke a "cytokine storm" in those individuals infected with SARS-CoV-2, which may lead to multiorgan failure. ${ }^{38}$ Governments and medical institutions must promote physical ac- tivity, healthy eating, and mental health care during such pandemics. Social media or web-based programs can help patients maintain healthy lifestyles. Active counseling to help people with metabolic dysregulation cope with barriers to healthier lifestyles would be helpful in this critical situation. ${ }^{39}$

One strength of this study is that we focused exclusively on regularly attending outpatients who were followed-up for 4 years to reduce bias. Nonetheless, the study population was from a single center and only individuals who visited at least twice a year during 2016-2020 were included. Thus, the results reported might not be representative of the broader population in Korea. We did not investigate changes in physical activity or dietary habits in the study subjects. Moreover, it was not possible to observe the actual occurrence of $\mathrm{CHD}$ given the short observation period. Instead, we used 10-year CHD risk based on the FRS, but this is a well-established tool that has been used widely for this purpose. ${ }^{17}$

In conclusion, we found that the COVID-19 pandemic and its preventive measures had a negative influence on cardiometabolic profiles in subjects with metabolic impairments. This might be because of decreased physical activity and unhealthy dietary patterns linked to preventive measures such as social distancing and lockdown. Movement of individuals decreased in many countries during the COVID-19 pandemic, thus we expect that a similar aggravation in cardiometabolic risks will be found in other countries affected by the pandemic. From a long-term perspective, encouraging home exercise and healthy homemade meals is strongly recommended to mitigate the unfavorable impact of COVID-19 and related government preventive policies on cardiometabolic risk.

\section{CONFLICTS OF INTEREST}

Bo Kyung Koo is an Associate Editor and Soo Lim is a Senior Editor of the journal. However, they were not involved in the peer reviewer selection, evaluation, or decision process of this article. Otherwise, no other potential conflicts of interest relevant to this article were reported.

This research was funded by Yuhan Corporation through a subcontract with Seoul National University Bundang Hospital. The funding agency had no role in the study design, data collection and analysis, decision to publish, or preparation of the manuscript. 


\section{ACKNOWLEDGMENTS}

This research was funded by Yuhan Corporation (Seoul, South Korea) through a subcontract with Seoul National University Bundang Hospital (Seongnam, South Korea) (06-2020-334).

\section{AUTHOR CONTRIBUTIONS}

Study concept and design: MS, BKK, and SL; acquisition of data: MS and SL; analysis and interpretation of data: MS and SL; drafting of the manuscript: MS and SL; critical revision of the manuscript: all authors; obtained funding: SL; administrative, technical, or material support: MS; and study supervision: SL.

\section{SUPPLEMENTARY MATERIALS}

Supplementary Figure 1 can be found via https://doi.org/10. 7570/jomes21046.

\section{REFERENCES}

1. Liu C, Feng X, Li Q Wang Y, Li Q Hua M. Adiponectin, TNF- $\alpha$ and inflammatory cytokines and risk of type 2 diabetes: a systematic review and meta-analysis. Cytokine 2016; 86:100-9.

2. Wu Z, McGoogan JM. Characteristics of and important lessons from the coronavirus disease 2019 (COVID-19) outbreak in China: summary of a report of 72314 cases from the Chinese Center for Disease Control and Prevention. JAMA 2020; 323:1239-42.

3. Ministry of Health. Stronger social distancing for 15 days, starting with the government [Internet]. Sejong: Ministry of Health; 2020 [cited 2021 Aug 1]. Available from: https://www. mohw.go.kr/eng/nw/nw0101vw.jsp?PAR_MENU_ID =1007\& MENU_ID $=100701 \&$ page $=1 \& C O N T$ SEQ $=353716$ (2020, accessed 5 Nov 2020)

4. Park IN, Yum HK. Stepwise strategy of social distancing in Korea. J Korean Med Sci 2020;35:e264.

5. Porzionato A, Emmi A, Barbon S, Boscolo-Berto R, Stecco C, Stocco E, et al. Sympathetic activation: a potential link between comorbidities and COVID-19. FEBS J 2020;287:3681-8.

6. Lim S, Bae JH, Kwon HS, Nauck MA. COVID-19 and diabetes mellitus: from pathophysiology to clinical management. Nat Rev Endocrinol 2021;17:11-30.

7. Guan WJ, Ni ZY, Hu Y, Liang WH, Ou CQ, He JX, et al. Clinical characteristics of coronavirus disease 2019 in China. N Engl J Med 2020;382:1708-20.

8. Codo AC, Davanzo GG, Monteiro LB, de Souza GF, Muraro SP, Virgilio-da-Silva JV, et al. Elevated glucose levels favor SARS-CoV-2 infection and monocyte response through a HIF-1 $\alpha /$ glycolysis-dependent axis. Cell Metab 2020;32:43746.e5.

9. Bansal R, Gubbi S, Muniyappa R. Metabolic syndrome and COVID 19: endocrine-immune-vascular interactions shapes clinical course. Endocrinology 2020;161:bqaa112.

10. Lim S, Lim H, Després JP. Collateral damage of the COVID-19 pandemic on nutritional quality and physical activity: perspective from South Korea. Obesity (Silver Spring) 2020;28: $1788-90$

11. Di Renzo L, Gualtieri P, Pivari F, Soldati L, Attinà A, Cinelli G, et al. Eating habits and lifestyle changes during COVID-19 lockdown: an Italian survey. J Transl Med 2020;18:229.

12. Mattioli AV, Ballerini Puviani M, Nasi M, Farinetti A. COVID19 pandemic: the effects of quarantine on cardiovascular risk. Eur J Clin Nutr 2020;74:852-5.

13. Yoo S, Lee KH, Lee HJ, Ha K, Lim C, Chin HJ, et al. Seoul National University Bundang Hospital's electronic system for total care. Healthc Inform Res 2012;18:145-52.

14. Shin Y, Moon JH, Chin HJ, Ferrannini E, Lim S. Glycemic efficacy and metabolic consequences of an empagliflozin addon versus conventional dose-increasing strategy in patients with type 2 diabetes inadequately controlled by metformin and sulfonylurea. Endocrinol Metab (Seoul) 2020;35:329-38.

15. Expert Panel on Detection, Evaluation, and Treatment of High Blood Cholesterol in Adults. Executive Summary of The Third Report of The National Cholesterol Education Program (NCEP) Expert Panel on Detection, Evaluation, And Treatment of High Blood Cholesterol In Adults (Adult Treatment Panel III). JAMA 2001;285:2486-97.

16. World Health Organization, Regional Office for the Western 
Pacific. The Asia-Pacific perspective: redefining obesity and its treatment. Sydney: Health Communications Australia; 2000.

17. Wilson PW, D’Agostino RB, Levy D, Belanger AM, Silbershatz H, Kannel WB. Prediction of coronary heart disease using risk factor categories. Circulation 1998;97:1837-47.

18. Kwon SY, Na YA. The assessment of Framingham risk score and 10 year CHD risk according to application of LDL cholesterol or total cholesterol. Korean J Clin Lab Sci 2016;48: 54-61.

19. van Buuren S, Groothuis-Oudshoorn K. Mice: multivariate imputation by chained equations in R. J Stat Softw 2011;45: $1-67$.

20. Altman DG, Bland JM. Interaction revisited: the difference between two estimates. BMJ 2003;326:219.

21. Zachary Z, Brianna F, Brianna L, Garrett P, Jade W, Alyssa D, et al. Self-quarantine and weight gain related risk factors during the COVID-19 pandemic. Obes Res Clin Pract 2020;14: 210-6.

22. Martinez-Ferran M, de la Guía-Galipienso F, Sanchis-Gomar F, Pareja-Galeano H. Metabolic impacts of confinement during the COVID-19 pandemic due to modified diet and physical activity habits. Nutrients 2020;12:1549.

23. Kim TH, Park Y, Myung J, Han E. Food price trends in South Korea through time series analysis. Public Health 2018;165: 67-73.

24. Fleischhacker SE, Evenson KR, Rodriguez DA, Ammerman AS. A systematic review of fast food access studies. Obes Rev 2011;12:e460-71.

25. Lim H, Lee HJ, Choue R, Wang Y. Trends in fast-food and sugar-sweetened beverage consumption and their association with social environmental status in South Korea. J Acad Nutr Diet 2018;118:1228-36.e1.

26. Pereira MA, Kartashov AI, Ebbeling CB, Van Horn L, Slattery ML, Jacobs DR Jr, et al. Fast-food habits, weight gain, and insulin resistance (the CARDIA study): 15-year prospective analysis. Lancet 2005;365:36-42.

27. Duffey KJ, Gordon-Larsen P, Jacobs DR Jr, Williams OD, Popkin BM. Differential associations of fast food and restaurant food consumption with 3-y change in body mass index: the Coronary Artery Risk Development in Young Adults Study.
Am J Clin Nutr 2007;85:201-8.

28. Pearson N, Biddle SJ. Sedentary behavior and dietary intake in children, adolescents, and adults: a systematic review. Am J Prev Med 2011;41:178-88.

29. Visscher TL, Seidell JC. Time trends (1993-1997) and seasonal variation in body mass index and waist circumference in the Netherlands. Int J Obes Relat Metab Disord 2004;28: 1309-16.

30. Ushigome E, Kitagawa N, Kitae A, Kimura T, Iwai K, Oyabu C, et al. Seasonal variation in home blood pressure and its relationship with room temperature in patients with type 2 diabetes. Diab Vasc Dis Res 2020;17:1479164119883986.

31. Ockene IS, Chiriboga DE, Stanek EJ 3rd, Harmatz MG, Nicolosi R, Saperia G, et al. Seasonal variation in serum cholesterol levels: treatment implications and possible mechanisms. Arch Intern Med 2004;164:863-70.

32. Rajkumar RP. COVID-19 and mental health: a review of the existing literature. Asian J Psychiatr 2020;52:102066.

33. Mattioli AV, Nasi M, Cocchi C, Farinetti A. COVID-19 outbreak: impact of the quarantine-induced stress on cardiovascular disease risk burden. Future Cardiol 2020;16:539-42.

34. Stephens MA, Wand G. Stress and the HPA axis: role of glucocorticoids in alcohol dependence. Alcohol Res 2012;34: 468-83.

35. Mattioli AV, Sciomer S, Cocchi C, Maffei S, Gallina S. Quarantine during COVID-19 outbreak: changes in diet and physical activity increase the risk of cardiovascular disease. Nutr Metab Cardiovasc Dis 2020;30:1409-17.

36. Cabandugama PK, Gardner MJ, Sowers JR. The renin angiotensin aldosterone system in obesity and hypertension: roles in the cardiorenal metabolic syndrome. Med Clin North Am 2017;101:129-37.

37. Azevedo MR, Araújo CL, Reichert FF, Siqueira FV, da Silva MC, Hallal PC. Gender differences in leisure-time physical activity. Int J Public Health 2007;52:8-15.

38. Michalakis K, Ilias I. SARS-CoV-2 infection and obesity: common inflammatory and metabolic aspects. Diabetes Metab Syndr 2020;14:469-71.

39. Patnode CD, Evans CV, Senger CA, Redmond N, Lin JS. Behavioral counseling to promote a healthful diet and physical 
activity for cardiovascular disease prevention in adults without known cardiovascular disease risk factors: updated evi- dence report and systematic review for the US preventive services task force. JAMA 2017;318:175-93. 